\title{
ON THE ESTIMATION OF NITRATES IN RIVER WATER.
}

\section{By Frank P. Perkins.}

Read before the Society of Public Analysts on 16th March, 1881.

ManY are the processes that have been devised for the estimation of nitrates ; nevertheless, the method here described may, perhaps, be found worthy of your consideration : not the less so from its constancy and extreme simplicity. I have observed that if 100 c.c. of the water to be examined are put into a perfectly bright and freshly ignited platinum dish, together with a very small portion of sodium chloride (the commercial salt may be used if previously ignited to get rid of any trace of organic matter it may contain), on introducing into the saline liquid a coil of magnesium (made from a piece of ribbon about three feet in length by simply coiling it round a glass rod, and subsequently cleansing it from oxide by immersing it in dilute hydrochloric acid and washing with water), immediately that contact between the platinum and magnesium is gained, electrical action ensues and the water is decomposed. At first the action is somewhat slow, but in a very few minutes a torrent of minute gas bubbles ascends through the liquid. Should the water contain nitrates these are reduced-through the action of the nascent hydrogen-and converted into ammonia. A slight elevation of temperature considerably hastens the decomposition, but in practice nothing is gained by this. During the experiment the platinum dish is covered with a clock glass, then placed on a plate of ground glass, and for further security a small bell jar, the mouth of which is also ground, is inverted over it, contact with the air being thus in a great measure prevented. Thus it rests during the night, or until the whole of the magnesium is dissolved. The convex surface of the clock glass is then rinsed with pure 
distilled water into the dish, and the electrolysed liquid, or a measured portion thereof, transferred to a flask, and the ammonia distilled off and nesslerized in the usual way.

As a platinum dish of the required size may not always be at hand, it has been my endeavour to arrange the experiment in a less costly manner without detracting from its completeness. The following arrangement will be found all that can be desired on this score. Into a wide-mouthed four-ounce bottle a round plate of platinum foil, perfectly clean, and of about the same diameter as the interior of the vessel, is placed and allowed to lie flat and loose on its bottom. To the mouth of the bottle a sound cork is fitted (a caoutchouc stopper must not be used) and through its centre a piece of quill tubing a few inches long, drawn out at one end to a fine orifice, and filled with beads or minute fragments of glass, is passed. Into this apparatus the water prepared as already shown is placed, and the coil of magnesium having been dropped in and the contents of the little tube moistened with water, the cork is fixed firmly in position and the decomposition allowed to proceed. At the conclusion of the experiment the little tube (which may contain traces of ammonia) and the under surface of the cork are rinsed into the larger vessel, the loss of ammonia being thus prevented. The determination of the ammonia is then made, a correction for the amount of free ammonia originally contained in the water being of course necessary. The working of the process will be seen from the following experiments.

Exeter Water.-Per 100,000 parts.

\begin{tabular}{|c|c|c|c|c|c|c|}
\hline No. $1 \quad \ldots$ & $\ldots$ & $\ldots$ & ... & $\cdot 2587$ & Nitrogen as & Nitrates. \\
\hline No. 2 (another sample) & $\ldots$ & $\cdots$ & $\ldots$ & $\cdot 2802$ & ", & ", \\
\hline The same water treated $b$ & Al. proce & ave & . & $\cdot 2583$ & , & " \\
\hline
\end{tabular}

In the discussion on the papers on Nitrates in Water, by Mr. West-Knights and Mr. Perkins,

Dr. Muter said they were scarcely in a position to discuss them at present, but it was very gratifying that the younger members of the Society should be coming forward so well lately. He suggested the desirability of postponing any discussion till they had had an opportunity of trying the processes.

Dr. Dupré said it seemed to him that the real way to get at nitric acid was to convert it into ammonia. It was the only philosophical way. The Brucine method laboured under the same disadvantage as the Indigo process-they did not know exactly what it jave, and it differed with various waters.

Mr. West-Knights, in replying, said that the Brucine test must not be put on a par with the Indigo process, because some compound of Brucine had, he believed, been produced in a crystalline form, and, therefore, it was quite as much a definite process as the Ammonia process. 